\title{
Pseudoxanthoma elasticum: Clinical phenotypes, molecular genetics and putative pathomechanisms
}

\author{
Qiaoli Li ${ }^{1}$, Qiujie Jiang ${ }^{1}$, Ellen Pfendner ${ }^{2}$, András Váradi ${ }^{3}$, and Jouni Uitto ${ }^{1, *}$ \\ ${ }^{1}$ Departments of Dermatology and Cutaneous Biology, and Biochemistry and Molecular Biology, \\ Jefferson Medical College, and Jefferson Institute of Molecular Medicine, Thomas Jefferson \\ University, Philadelphia, PA 19107, USA \\ ${ }^{2}$ GeneDx Inc., Gaithersburg, MD 20877, USA \\ 3Institute of Enzymology, Hungarian Academy of Sciences, Budapest, Hungary
}

\begin{abstract}
Pseudoxanthoma elasticum (PXE), a prototype of heritable multi-system disorders, is characterized by pathologic mineralization of connective tissues, with primary clinical manifestations in the skin, eyes and the cardiovascular system. The causative gene was initially identified as $A B C C 6$ which encodes an $\mathrm{ABC}$ transporter protein (ABCC6) expressed primarily in the liver and the kidneys. The critical role of $A B C C 6$ in ectopic mineralization has been confirmed by the development of $A b c c \sigma^{--}$knock-out mice which recapitulate the features of connective tissue mineralization characteristic of PXE. Over 200 distinct loss-of-function mutations representative of over 1000 mutant alleles in $A B C C 6$ have been identified by streamlined mutation detection strategies in this autosomal recessive disease. More recently, missense mutations in the $G G C X$ gene, either in compound heterozygous state or digenic with a recurrent ABCC6 nonsense mutation (p.R1141X), have been identified in patients with PXE-like cutaneous findings and vitamin K-dependent coagulation factor deficiency. $G G C X$ encodes a carboxylase which catalyzes $\gamma$-glutamyl carboxylation of coagulation factors as well as of matrix gla protein (MGP) which in fully carboxylated form serves as a systemic inhibitor of pathologic mineralization. Collectively, these observations suggest the hypothesis that a consequence of lossof-function mutations in the $A B C C 6$ gene is the reduced vitamin $\mathrm{K}$-dependent $\gamma$-glutamyl carboxylation of MGP, with subsequent connective tissue mineralization. Further progress in understanding the detailed pathomechanisms of PXE should provide novel strategies to counteract, and perhaps cure, this complex heritable disorder at the genome-environment interface.
\end{abstract}

\section{Keywords}

Heritable skin diseases; Pathologic connective tissue mineralization; $\mathrm{ABC}$ transporters

\section{Phenotypic Spectrum of PXE}

Pseudoxanthoma elasticum (PXE) is a multisystem genetic disorder characterized by dystrophic mineralization of soft connective tissues in a number of organs, including the

\footnotetext{
*Address for Correspondence: Jouni Uitto, MD, Ph.D., Department of Dermatology and Cutaneous Biology, Jefferson Medical College, 233 South $10^{\text {th }}$ Street, Suite 450 BLSB, Philadelphia, PA 19107, U.S.A. Tel: 215-503-5785, Fax: 215-503-5788, Jouni.Uitto@jefferson.edu.

Dr. Pfendner is employed by GeneDx, Inc., a commercial laboratory specializing in mutation analysis. The other authors have no financial conflicts to declare.
} 
skin, the eyes, and the arterial blood vessels (1-3). This disease was initially delineated as a clinical entity, distinct from xanthomas (hence pseudoxanthoma), over a century ago, and during the ensuing decades, various clinical observations, histopathology, and ultrastructural findings suggested that the primary pathology resides in the elastic fibers. Consequently, PXE was considered as a prototype of heritable connective tissue disorders with primary involvement of the elastic fiber system (2).

The clinical manifestations of classic PXE center on three major organ systems of the body, viz., skin, eyes, and the cardiovascular system. The primary cutaneous lesions are small, yellowish papules on the predilection sites at flexural areas, and these lesions progressively coalesce into larger plagues of inelastic, leathery skin with yellowish hue (Fig. 1) (3). Histopathologic evaluation of skin reveals accumulation of basophilic elastotic material, as revealed by Hematoxylin-Eosin stain, and characteristically, these elastotic structures become mineralized in a progressive manner over the lifetime of the affected individuals (von Kossa and Alizarin Red stains in Fig. 1). The eye manifestations consist of angioid streaks, and bleeding from the choroidal vessels can result in loss of visual acquity and, relatively rarely, in central blindness. The cardiovascular manifestations derive from mineralization of arterial blood vessels, and include gastrointestinal bleeding, intermittent claudication, hypertension, and, occasionally, early myocardial infarcts. The precise incidence of PXE is undefined and the estimates vary widely (see 2, 4). In general populations, the estimates in the 1 in 50,000 to 1 in 70,000 range may be representative.

While PXE is associated with considerable morbidity and occasional mortality from cardiovascular complications, the phenotypic spectrum is highly variable with both interand intra-familial heterogeneity, and involvement of any given organ system may be predominant in certain families. This variability has presented a diagnostic challenge, compounded by the fact that clinical manifestations are rarely present at birth and often become evident not until the second or third decade of life, thus complicating and prolonging the process leading to correct diagnosis on the clinical basis. Adding to the complexity were early suggestions that both autosomal dominant and autosomal recessive forms of the disease exist (see ref. 2). However, recent advances of molecular genetics of PXE have established that PXE is exclusively an autosomal recessive disorder, and the suggestions of autosomal dominant forms, which were based on the presence of the disease in two subsequent generations in a few families, can now be explained on the basis of pseudo-dominance often due to familial consanguinity (5). Microscopic changes in the elastic fibers of the skin in heterozygous carriers, who have an essentially normal or limited and atypical clinical phenotype, have been reported (6). Furthermore, a recent study has suggested that heterozygous carriers of an $A B C C 6$ mutation may occasionally have serious manifestations, particularly affecting the eyes (7). These heterozygous carriers have also been suggested to be at increased risk for premature coronary artery disease (8), suggesting that heterozygous carriers may have a limited or subclinical phenotype.

\section{Molecular Genetics}

Since the primary pathology of PXE was observed to affect the elastic fibers in the skin, the genes involved in the synthesis and assembly of the elastic fiber network were initially considered as the primary candidates for mutations; these included elastin (ELN) on chromosome 7q, elastin associated microfibrillar proteins, such as fibrillin 1 and fibrillin 2 ( $F B N 1$ and $F B N 2$ ) on chromosomes 15 and 5, and lysyl oxidase $(L O X)$ also on chromosome 15. However, genetic linkage analyses excluded these chromosomal regions $(9,10)$. Subsequent studies utilizing positional cloning approaches provided strong evidence for linkage to the short arm of chromosome 16 , and the critical interval was eventually refined by the use of informative recombinants to consist of approximately $500 \mathrm{~kb}(11,12)$. 
Examination of the existing genome database revealed that this candidate region contained four genes, none of which had an obvious connection to the extracellular matrix of connective tissues in general or to the elastic fiber network in particular. Systematic sequencing of these candidate genes resulted in identification of the $A B C C 6$ gene as the one harboring mutations in PXE (13-16). This gene encodes a putative transmembrane transporter protein, ABCC6 (also known as multidrug resistance-associated protein 6 MRP6), a member of the family of ATP-binding cassette (ABC) proteins. The $A B C C 6$ gene is primarily expressed in the liver, to a lesser extent in the proximal tubules of kidneys, and at very low level, if at all, in tissues affected in PXE $(17,18)$. These observations raised an apparent dilemma concerning the pathomechanism of PXE: How do mutations in the gene expressed primarily in the liver result in mineralization of skin, eyes and blood vessels in peripheral tissues (19)? While the mineral deposits in the affected tissues are known to consist of calcium and phosphate, the precise mechanisms leading to pathologic mineralization remain unclear, and specifically, the substrate specificity of ABCC6 is currently unknown.

The $A B C C 6$ gene is encoded in 31 exons spanning $\sim 75 \mathrm{~kb}$ of the human genome on human chromosome 16p13.1 (Fig. 2). This region also contains two closely related but nonfunctional $5^{\prime}$ pseudogenes, $A B C C 6-\psi 1$ and $A B C C 6-\psi 2$, which correspond to exons 1-9 and 1-4 of the coding gene, respectively (20). A close sequence similarity (over 99\%) between the two pseudogenes and the coding gene complicates mutation detection, although coding gene specific primer sets have been designed for each exon facilitating analysis without interference from the pseudogene sequences (21). The $A B C C 6$ gene is transcribed into an $\sim 5 \mathrm{~kb}$ mRNA and translated into a $165 \mathrm{kD}$ protein of 1503 amino acids. This protein has three hydrophobic transmembrane domains (TMD) containing a total of 17 transmembrane helices as well as two intracellular nucleotide binding folds (NBFs), each containing highly conserved Walker motifs which are critical for the function of the protein in ATP-driven transmembrane transport (Fig. 2). Based on sequence homology with other members of the $\mathrm{C}$ family of $\mathrm{ABC}$ proteins, particularly the prototypic $\mathrm{ABCC} 1$, the ABCC6 protein has been postulated to function as an efflux transporter in the liver. The in vivo substrate specificity of this putative transporter is currently unknown, but recent studies have shown that it can function as a transmembrane transporter of polyanionic, glutathioneconjugated molecules in vitro $(22,23)$.

The critical role of the $A B C C 6$ gene in the pathogenesis of PXE has also been confirmed by development of transgenic mice through targeted ablation of the corresponding mouse gene, $A b c c 6(24,25)$. The $A b c c \sigma^{--}$mice recapitulate certain cardinal features of human PXE, including progressive tissue mineralization.

\section{Mutations in the $A B C C 6$ Gene Causing PXE}

To date, over 200 distinct mutations in the $A B C C 6$ gene have been described representing over 1000 mutant alleles $(21,26)$. The types of mutations include missense and nonsense mutations in 28 of the 31 exons of $A B C C 6$, intronic mutations causing miss-splicing, small deletions and insertions, as well as large deletions spanning part or the entire coding region and sometimes including flanking genes (Fig. 2). Two mutations are recurrent and of high frequency: First, the most common recurring mutation, particularly in Caucasian individuals, is p.R1141X in exon 24, with a prevalence of $\sim 30 \%$ of all PXE mutations. Secondly, a recurrent, AluI-mediated deletion of exons 23-29 (del23-29; p.A999-S1403del) of the $A B C C 6$ gene has been found on at least one allele in up to $20 \%$ of US and $12 \%$ of European patients (26). Both PCR only and PCR/restriction enzyme digestion assays have been developed to identify these recurrent mutations. Nevertheless, only $\sim 10 \%$ of all patients in a recent large US and European study (21) were homozygous or compound heterozygous for 
p.R1141X and del23-29 mutations, indicating that $~ 90 \%$ of all individuals in these PXE populations will require further analysis to identify the second mutation or both mutations in the $A B C C 6$ gene causing their disease. Identification of additional recurrent nonsense mutations (p.Q378X in exon 9, p.R518X in exon 12, and p.R1164X in exon 24) as well as clustering of the missense mutations to exons 24 and 28 corresponding to the NBFs that are critical for the ATP binding and hydrolysis have allowed development of streamlined mutation detection strategies to facilitate identification of mutations in the ABCC6 gene with the overall detection rate of up to $99 \%$ (for review see ref. 26). Thus, mutation analysis is now readily available for individuals with family history of PXE.

Identification of mutations in the $A B C C 6$ gene can be used for confirmation of the clinical diagnosis, carrier detection, and presymptomatic identification of affected individuals with family history of PXE. In this context, it should be noted that the average age of clinical diagnosis, based on skin findings, of patients with PXE is around 8-12 years of age (4). Although no specific treatment is presently available for this condition, early identification of the disease and increased surveillance for its sequela will hopefully improve the quality of life of the affected individuals. Finally, prenatal testing is feasible although rarely contemplated by the parents who consider the risk for recurrence.

\section{Homology Models of ABC Transporters}

Recent milestones in $\mathrm{ABC}$ transporter research include determination of high-resolution, three-dimensional structures of bacterial ABC export pumps (27-29). These structures conform with earlier biochemical data and provide potentially good templates for homology model building for human $\mathrm{ABC}$ transporters. In fact, we have embarked upon such an in silico project and generated a homology model of human ABCC6 (Fig. 3). The first transmembrane domain $\left(\mathrm{TMD}_{0}\right)$, which is a unique element of the C-type transporters of the $\mathrm{ABC}$ family, could not be included into the model building; the same is true for the flexible loop connecting the two halves of the protein. Similar models based on the same principle have been developed for human ABCC1 (30) and human ABCB1 (31).

A side view of human ABCC6 is presented in Figure 3. The two halves of the molecule are indicated with different colors. PXE-associated missense mutations are indicated on the homology model (red). An analysis of the distribution of missense mutations revealed that mutations of residues participating in domain-domain interactions, which provide the structural basis of "informational transmission" and are in contact between the two catalytic (ABC) domains, are $3.5-4.1$ fold more frequent than the average mutational rate of the overall polypeptide chain.

\section{Pathomechanistic Consequences of ABCC6 Mutations}

As indicated above, the physiologic role of ABCC6 protein is currently unknown, and in particular, its ligands as putative efflux transporter in vivo remain unknown. To explain the potential mechanisms leading from ABCC6 mutations to pathologic mineralization in peripheral tissues in PXE, at least two general theories have been advanced.

"The metabolic hypothesis" postulates that absence of functional ABCC6 activity, primarily in the liver, results in deficiency of circulating factor(s) that are physiologically required to prevent aberrant mineralization under normal calcium and phosphate homeostatic conditions (Fig. 4) (32,33). In support of the metabolic hypothesis are several both clinical and experimental observations in patients with PXE as well as in the $A b c c 6^{-1}$ mouse that serves as a model for human PXE. First, the clinical findings in patients with PXE are rarely present at early childhood, the onset of clinical manifestations is considerably delayed, and the ensuing progression of the disease is slow, presumably due to 
continued accumulation of mineral in soft connective tissues of the affected organs. In the $A b c c 6^{-1-}$ mice, no evidence of aberrant mineralization is noted until $\sim 4-5$ weeks after the birth (24). Secondly, serum from patients with PXE as well as from $A b c c \sigma^{-1}$ mice lack the capacity to prevent calcium/phosphate precipitation in an in vitro assay utilizing human smooth muscle cell cultures (34). Furthermore, serum from patients with PXE, when added to tissue culture medium, has been shown to alter the expression of elastin by fibroblasts in cultures, suggesting the presence or absence of specific circulating factors (35). Finally, recent skin grafting studies in wild-type and $A b c c \sigma^{-1-}$ mice have supported the notion that circulating factor(s) play a critical role in determining the degree of mineralization (36). In the latter studies, muzzle skin from $A b c c \sigma^{--}$mice and their wild-type littermates were grafted onto the back of $A b c c \sigma^{+/+}$or $A b c c 6^{--}$mice. The muzzle skin of mice contains vibrissae, and a connective tissue capsule surrounding the bulb of vibrissae becomes reproducibly calcified in $A b c c 6^{-1-}$ mice at $\sim 5$ weeks, thus serving as an early and quantifiable biomarker of the mineralization process in this mouse model of PXE (34). When muzzle skin from $A b c c 6^{+/+}$mice was grafted onto the back of $A b c c \sigma^{--}$mice at 4 weeks of age, mineralization ensued in subsequent two months. In contrast, no mineralization was observed in the muzzle skin from $A b c c \sigma^{-1}$ mice transplanted onto the back of $A b c c \sigma^{+/+}$mice. In this kind of grafting model, vascular capillaries in the graft regress while new vascular ingrowth occurs from the recipient wound bed to replace the regressing vessels (37). The survival of skin grafts is, therefore, dependent on reestablishment of circulation in the graft from the recipient animal, and consequently, all survived grafts are supplied by blood of the recipient mice. Since the $A b c c \sigma^{--}$mouse skin graft did not develop mineralization when placed onto the $A b c c \sigma^{+/+}$mouse, but the skin from wild-type mouse showed mineralization after grafting onto the $A b c c 6^{-1-}$ mouse, these findings suggest that circulating factors in the recipient's blood play a critical role in determining the degree of mineralization of the graft, irrespective of graft genotype.

"The PXE cell hypothesis", postulates that lack of ABCC6 expression in the resident cells in affected tissues, such as skin fibroblasts or arterial smooth muscle cells, alters their biosynthetic expression profile and cell-cell and cell-matrix interactions associated with changes in the proliferative capacity $(38,39)$. In support of this postulate, it has been demonstrated that cultured skin fibroblasts from patients with PXE depict enhanced synthesis of elastin and glycosaminoglycan/proteoglycan complexes, but they also demonstrate enhanced degradative potential due to elevated matrix metalloproteinase-2 activity (40). In support of this postulate are also the histopathological and ultrastructural demonstrations that the elastic structures in the skin that become mineralized in PXE do not appear morphologically normal and they have been suggested to have a composition different from elastin isolated from normal tissues $(41,42)$.

\section{Related Conditions with PXE-like Cutaneous Findings}

In addition to the classic form of the disease, PXE-like clinical features, including aberrant mineralization of elastic structures in the skin, have been reported in a number of apparently unrelated clinical, both acquired and genetic conditions (43). Among the acquired conditions, PXE-like cutaneous changes may be associated with multiple pregnancy, endstage renal disease, or topical exposure to mineral-containing fertilizers. In these cases, mineralization of skin may result from metabolic abnormalities affecting calcium and/or phosphate homeostasis or from direct deposition of the mineral salts through the skin with affinity for elastic structures. However, the pathomechanistic details and role of any predisposing genetic factors in these situations are unknown.

PXE-like cutaneous changes with ocular findings have also been found in a large portion, perhaps as many as in $20 \%$, of patients with $\beta$-thalassemia and sickle cell anemia, yet no 
gene defects in $A B C C 6$ in these patients could be found $(44,45)$. These and similar observations have been the basis for suggestions that generalized and local oxidative imbalance may lead to clinical PXE manifestations also in classic forms of PXE. This hypothesis has been supported by observations that fibroblast cultures derived from the skin of patients with PXE demonstrate changes in oxidative stress markers in vitro (46).

Subsequently, genetic variations in antioxidant genes have been suggested to be a risk factor for early disease onset in PXE (47). Specifically, restriction fragment length polymorphisms and allele-specific PCR analyses were used to evaluate the distribution of single-nucleotide polymorphisms in the genes encoding catalase, superoxide dismutase 2 , and glutathione peroxidase 1 in DNA samples from PXE patients and healthy controls. The genetic variants investigated in this study have been shown to affect the activities of these antioxidant enzymes. A correlation between the patients' genotype with respect to polymorphisms in these genes and the age at disease onset was found (47).

Utilizing the $A b c c 6^{--}$mouse as a model of PXE, we have been able to confirm the presence of chronic oxidative stress, as reflected by reduced total antioxidant capacity and the presence of enhanced protein oxidation and lipid peroxidation markers (48). These findings in animals, therefore, support previous observations made on cultured fibroblasts from patients with PXE suggesting mild, chronic oxidative stress in this disease. The key observation in our study was, however, that antioxidant diet containing vitamins $\mathrm{C}$ and $\mathrm{E}$, selenium and $\mathrm{N}$-acetylcysteine was effective in counteracting the oxidative stress, but it did not modify the process of aberrant mineralization of connective tissues in PXE mice (48). We concluded, therefore, that as ectopic mineralization is the pathologic hallmark of PXE responsible for the clinical manifestations, it is unlikely that oxidative stress plays a major causal role in the pathomechanism of PXE. It is more likely that oxidative stress reflects the generalized condition of these mice as a consequence of the disease, as encountered in a number of clinical situations and in chronologic aging. These findings have implications for potential treatment of PXE. Specifically, previous demonstrations of oxidative stress in cultured PXE fibroblasts (46), a finding corroborated by our in vivo study (48), raised the possibility that ingestion of antioxidants may be beneficial in counteracting the disease process in PXE. Our findings in an animal model do not support such a suggestion, although carefully controlled clinical trials on patients with PXE would potentially provide an unequivocal answer.

Meanwhile, the "redox status" hypothesis of the cellular mechanism of PXE has also been put forward. This model aims to rationalize the correlation between the ABCC6 mutations and soft tissue mineralization on the basis of the potential contribution of ABCC transporters in maintaining the intracellular redox potential. Upon oxidative stress, an immediate defense reaction is the conversion of glutathione (GSH) to its oxidized form, GSSG. This reaction effectively eliminates the reactive oxidizing species, but results in the change of the redox potential (Nerst potential) of the intracellular compartment. By removing GSSG, the Nerst potential can be maintained by a quick response before GSH synthesis fills up the GSHpool. It has been demonstrated that removal of GSSG from the cell is facilitated by ABCC1 in the aorta endothelium (49), and GSSG transport by ABCC1 has also been documented by an in vitro biochemical transport assay (50). If such a transport mechanism is absent in the cell, restoration of the redox potential following oxidative stress may be delayed. The vitamin K-cycle is a redox cycle, and its turnover is sensitive to the redox potential of the milieu. Thus, the proper kinetics of the vitamin K-cycle is essential in MGP- $\gamma$-glutamyl carboxylation, and in PXE-like syndrome missense mutations in the $G G C X$ gene "slow down" the vitamin K cycle (see below). According to the "redox status" hypothesis in PXE, the altered redox potential may be responsible for the lower turnover of cycle. Both mechanisms could lead to under-carboxylation of MGP and soft tissue calcification (51). 


\section{Phenotype Modifying Factors}

A number of modifying factors, both genetic and environmental, have been suggested to play a role in PXE phenotypic expression. One of the recently identified genetic factors involves polymorphisms in the promoter of the SPP1 gene (secreted phosphoprotein 1; also known as OPN, osteopontin) (52). Screening of this promoter revealed nine different sequence variations, and three of them (c.-1748A $\rightarrow$ G, c.-155_156insG, and c.

244_245insTG) were significantly more frequent in PXE patients than in matched controls. The odds ratio for PXE among the carriers of these three alleles were 2.16, 2.41 and 1.97, respectively. One haplotype was also shown to be significantly associated with reduced risk for PXE. It was concluded, therefore, that polymorphisms in the SPP1 promoter are a genetic risk factor contributing to PXE susceptibility (52). As discussed below, $A B C C 6$ haplosufficiency may also synergize the effects of the $G G C X$ gene, encoding $\gamma$-glutamyl carboxylase protein, in patients with PXE and multiple coagulation factor deficiency.

Diet has also been suggested to play a role in modifying the severity of PXE, and in particular, high intake of dairy products rich in calcium and phosphate during childhood and adolescence has been suggested to accelerate the clinical presentation $(43,53)$. It should be noted, however, that these retrospective, and somewhat anecdotal, studies have epidemiological weaknesses. Furthermore, recent preliminary prospective studies have suggested that treatment of patients with PXE with aluminum hydroxide, an oral phosphate binder can result in significant clinical improvement of skin lesions, and no progress of eye disease was noted in any of the six patients examined at a one-year follow up point (54). Collectively, these findings suggested that abnormalities in calcium/phosphate metabolism may contribute to the pathologic mineralization process in PXE. We have attempted to verify the role of dietary modifications and a phosphate binder utilizing the PXE mouse model $\left(A b c c 6^{--}\right)$as target (55). The experimental diet consisted of high phosphorous, low calcium and low magnesium, and the degree of mineralization was determined in $\mathrm{H} \& \mathrm{E}$ stained sections utilizing computerized morphometric analysis and bio-chemical assays to measure the calcium and phosphate content of the vibrissae, the site of early mineralization in these mice. The results indicated increased mineralization in the $A b c c 6^{--}$mice fed a standard diet or a diet with mineral modifications as compared with control mice fed a standard diet (55). Collectively, these preliminary studies suggested that dietary factors may play a role in the mineralization process in PXE, but the precise role of individual dietary minerals, such as calcium and phosphate, as well as phosphate binders clearly merits further investigation.

\section{PXE-like Cutaneous Findings in Patients with Coagulation Defects}

An intriguing phenotypic observation with potential pathomechanistic implications involves cases with features of PXE in association with vitamin K-dependent multiple coagulation factor deficiency (56-58). These patients demonstrate primary cutaneous lesions with PXElike phenotype, i.e., small yellowish papules which tend to coalesce. In addition, the skin demonstrates excessive folding and sagging with loss of recoil (Fig. 1). Thus, these patients have been described as having combined cutaneous features of both PXE and cutis laxa (58). The cutaneous lesions in these patients depict profound mineralization, similar to that in PXE (Fig. 1). In addition to skin findings, some of these patients demonstrate angioid streaks (58). Molecular analysis of some of these patients has revealed mutations in the $G G C X$ gene which encodes an enzyme required for $\gamma$-glutamyl carboxylation of proteins, such as the vitamin K-dependent coagulation factors and MGP (58).

Particularly illustrative of the complexity of this clinical situation is a multiplex pedigree that we have recently examined by molecular analysis of both $A B C C 6$ and $G G C X$ genes 
(Fig. 5) (59). The proband is a female who at around age 10 years began to develop progressively loose, sagging and redundant skin, and an initial diagnosis of cutis laxa was made. At the age of 15 years, proband skin changes were seen (Fig. 1). The patient also had a coagulation disorder with prolonged bleeding time and deficiency in a number of coagulation factors. The proband had a sister, three years older, with similar skin changes beginning in her early teens, as well as the coagulation disorder. They had a brother who was clinical normal. Examination of the members of the nuclear pedigree revealed that the father of the proband is clinically normal, while the mother and her fraternal twin sister had distinct folding of the skin, particularly in the axillary areas. They also had characteristic yellowish papules consistent with PXE on the sides of the neck and axillary areas. Neither the mother nor her sister had evidence of a coagulation disorder. Histopathology of the individuals with skin findings revealed aberrant mineralization of basophilic elastotic material confirming the diagnosis of PXE (Fig. 1) (59).

This family was first analyzed for the $A B C C 6$ gene mutations by a streamlined mutation detection strategy recently proposed for this gene $(21,26)$. The analysis revealed the presence of a recurrent mutation, p.R1141X, in the peripheral blood DNA in several family members but not in the proband herself or in her sister (Fig. 5). These individuals were heterozygous for the p.R1141X mutation, and no other $A B C C 6$ mutation could be disclosed in this family. Considering the clinical association of PXE-like cutaneous findings with coagulation disorder in this family, we also sequenced the GGCX and VKORC1 genes which are associated with combined deficiency of the vitamin K-dependent coagulation factors. While no mutation was detected in VKORC1, two distinct missense mutations in $G G C X$ could be detected: p.V255M and p.S300F. Correlation of the clinical findings with the genotypes revealed that the proband and her sister were compound heterozygotes for the two $G G C X$ missense mutations, potentially explaining their hematologic findings. In contrast, individuals who were heterozygous carriers of the $A B C C 6$ nonsense mutation p.R1141X were also heterozygous carriers of one of the $G G C X$ missense mutations. Specifically, the finding of the $G G C X$ missense mutation p.V255M in combination of the $A B C C 6$ nonsense mutation p.R1141X suggests the possibility of digenic inheritance of their cutaneous findings (59). Importantly, however, no $A B C C 6$ mutations were found in the proband and her sister, who were compound heterozygotes for $G G C X$ missense mutations, confirming previous observations (58) that the $G G C X$ gene mutations can cause PXE-like cutaneous changes.

\section{The Pathomechanistic Role of Matrix Gla Protein}

Subsequent to identification of missense mutations in $G G C X$ encoding the $\gamma$-carboxylase protein we demonstrated that these mutations resulted in markedly reduced enzyme activity, thus explaining the coagulation problems in the proband and her sister who were compound heterozygotes for these mutations (59). The profound skin findings in these individuals, with mineralization, further suggested that reduced $\boldsymbol{\gamma}$-glutamyl carboxylase activity may contribute to the skin phenotype. MGP is a low-molecular-weight protein that has the capacity to prevent unwanted mineralization under normal homeostatic levels of calcium and phosphorus (51). However, in order to be active, this protein has to be in fully carboxylated form (cMGP) while under-carboxylated MGP (ucMGP) is inactive. We postulated, therefore, that as a result of reduced $\gamma$-glutamyl carboxylase activity due to mutations in $G G C X$, the degree of carboxylation of MGP is reduced promoting aberrant mineralization. Indeed, immunohistochemical staining of skin biopsy specimens from patients with extensive mineralization of the dermis revealed an abundance of the undercarboxylated form while very little of the fully carboxylated form of MGP was present (Fig. 6). In control tissue specimens, the total amount of MGP appeared reduced, and there was very little, if any, of the ucMGP. These and related observations clearly suggested that 
under-carboxylation of MGP plays a role in aberrant mineralization of connective tissues in patients with $G G C X$ gene mutations, with and without associated $A B C C 6$ genetic lesions (Fig. 7). This mechanism may also be applicable to traditional PXE, a proposition that has been supported by recent electron microscopic examination of skin of patients with PXE and by analysis of the carboxylation status of MGP in $A b c c 6^{-/}$mice $(60,61)$.

An unresolved question is, however, how the absence of ABCC6 activity, a putative transmembrane transporter expressed primarily in the liver, contributes to reduced $\gamma$ glutamyl carboxylation of MGP, without obvious coagulation defect. A testable hypothesis revolves around the possibility that ABCC6 participates in cellular transport and potentially redistribution of vitamin $\mathrm{K}$, and specifically its reduced form $\left(\mathrm{KH}_{2}\right)$, an obligatory co-factor of $\gamma$-glutamyl carboxylase (Fig. 7) (62,63). More precisely, one could postulate that $\mathrm{KH}_{2}$, either alone or conjugated with GSH (64), could serve as a transport substrate for ABCC6. If so, in the absence of ABCC6 transport activity, the concentration of $\mathrm{KH}_{2}$ in the circulation as well as in peripheral cells, such as dermal fibroblasts, would be reduced leading to deficient $\gamma$-carboxylation of MGP and subsequent mineralization of adjacent connective tissues (Fig. 7). This postulate, if proven correct, would then raise the possibility that administration of appropriate forms of vitamin $\mathrm{K}$ or its derivatives might counteract the progressive mineralization of connective tissues in PXE and might ameliorate, or even cure, this currently intractable disease.

\section{Clinical Implications}

As with many genetic disorders, in spite of spectacular progress in understanding the molecular basis, there have been limited advances in treatment and cure for PXE. The most recent advances in terms of diagnosis and prognostication of this disease have been the identification of the gene harboring mutations and the clarification of autosomal recessive as the sole inheritance pattern. Attempts to establish genotype/phenotype correlations have yielded little clinically useful information other than the fact that as PXE patients age the symptoms seem to get worse, probably due to progressive accumulation of calcium phosphate in their tissues. Presumably, therefore, continuous age-associated accumulation of mineral deposits in the affected tissues is the explanation for the progressive phenotype. Individuals affected with PXE are encouraged to have frequent physical examinations, especially to screen for ocular and cardiovascular complications. Surgical interventions of skin for cosmetic improvement as well as peripheral and coronary arteries for vascular complications have been reported. For ocular complications, laser therapy to counteract retinal bleeding and experimental surgical translocation of the macula to improve vision have been advocated with conflicting results $(65,66)$. Meanwhile, continued progress in understanding the pathomechanisms of PXE may provide novel strategies to counteract this, currently intractable, disorder.

\section{Acknowledgments}

We thank Carol Kelly for assistance. The authors' original studies were performed in collaboration with Drs. Kathleen Berkner, Leon Schurgers, Masayuki Endoh, John Klement, and Jennifer LaRusso. László Barna and Krisztina Fülöp (Institute of Enzymology, Hungarian Academy of Sciences) assisted in homology model building. We appreciate the comments by Drs. Brian Carr, Joel Rosenbloom, and Sharon Terry. The authors' original studies were supported by the United States Department of Health and Human Services, NIH/NIAMS grants R01AR28450, R01AR52627 and R01AR55225, by PXE International, and by OTKA Research Grants (Hungary). During this study, Dr. Váradi was a Fulbright Scholar at Jefferson Medical College, Philadelphia. Dr. Jiang is the recipient of a Research Career Development Award from Dermatology Foundation. 


\section{References}

1. Neldner, KH.; Struk, B. Pseudoxanthoma elasticum. In: Royce, PM.; Steinmann, B., editors. Connective tissue and its heritable disorders: Molecular, genetic and medical aspects. Wiley-Liss, Inc.; New York: 2002. p. 561-583.

2. McKusick, VA. Heritable disorders of connective tissues. 4th. Mosby; 1972.

3. Uitto, J.; Ringpfeil, F. Heritable diseases affecting the elastic fibers: Cutis laxa, pseudoxanthoma elasticum and related disorders. In: Rimoin, DL.; Connor, JM.; Pyeritz, RE.; Korf, BR., editors. Principles and practice of genetics. Fifth. Churchill Livingstone; Philadelphia: 2007. p. 3647-3670.

4. Chassaing N, Martin L, Calvas P, Le Bert M, Hovnanian A. Pseudoxanthoma elasticum: A clinical, pathophysiological and genetic update including 11 novel ABCC6 mutations. J Med Genet. 2005; 42:881-892. [PubMed: 15894595]

5. Ringpfeil F, McGuigan K, Fuchsel L, et al. Pseudoxanthoma elasticum is a recessive disease characterized by compound heterozygosity. J Invest Dermatol. 2006; 126:782-786. [PubMed: 16410789]

6. Martin L, Chassaing N, Delaite D, Esteve E, Maitre F, Le Bert M. Histological skin changes in heterozygote carriers of mutations in ABCC6, the gene causing pseudoxanthoma elasticum. J Eur Acad Dermatol Venereol. 2007; 21:368-373. [PubMed: 17309461]

7. Martin L, Maître F, Bonicel P, et al. Heterozygosity for a single mutation in the ABCC6 gene may closely mimic PXE: consequences of this phenotype overlap for the definition of PXE. Arch Dermatol. 2008; 144:301-306. [PubMed: 18347285]

8. Trip MD, Smulders YM, Wegman JJ, et al. Frequent mutation in the ABCC6 gene (R1141X) is associated with a strong increase in the prevalence of coronary artery disease. Circulation. 2002; 106:773-775. [PubMed: 12176944]

9. Christiano AM, Lebwohl MG, Boyd CD, Uitto J. Workshop on pseudoxanthoma elasticum: molecular biology and pathology of the elastic fibers. Jefferson Medical College, Philadelphia, Pennsylvania. J Invest Dermatol. 1992; 99:660-663. [PubMed: 1431233]

10. Raybould MC, Birley AJ, Moss C, Hultén M, McKeown CM. Exclusion of an elastin gene (ELN) mutation as the cause of pseudoxanthoma elasticum (PXE) in one family. Clin Genet. 1994; 45:48-51. [PubMed: 8149653]

11. Le Saux O, Urban Z, Göring HH, et al. Pseudoxanthoma elasticum maps to an 820-kb region of the p13.1 region of chromosome 16. Genomics. 1999; 62:1-10. [PubMed: 10585762]

12. Cai L, Struk B, Adams MD, et al. A 500-kb region on chromosome 16p13.1 contains the pseudoxanthoma elasticum locus: high-resolution mapping and genomic structure. J Mol Med. 2000; 78:36-46. [PubMed: 10759028]

13. Ringpfeil F, Lebwohl MG, Christiano AM, Uitto J. Pseudoxanthoma elasticum: mutations in the MRP6 gene encoding a transmembrane ATP-binding cassette (ABC) transporter. Proc Natl Acad Sci USA. 2000; 97:6001-6006. [PubMed: 10811882]

14. Le Saux O, Urban Z, Tschuch C, et al. Mutations in a gene encoding an ABC transporter cause pseudoxanthoma elasticum. Nat Genet. 2000; 25:223-227. [PubMed: 10835642]

15. Bergen AA, Plomp AS, Schuurman EJ, et al. Mutations in ABCC6 cause pseudoxanthoma elasticum. Nat Genet. 2000; 25:228-231. [PubMed: 10835643]

16. Struk B, Cai L, Zäch S, et al. Mutations of the gene encoding the transmembrane transporter protein ABC-C6 cause pseudoxanthoma elasticum. J Mol Med. 2000; 78:282-286. [PubMed: 10954200]

17. Belinsky MG, Kruh GD. MOAT-E (ARA) is a full length MRP/cMOAT subfamily transporter expressed in kidney and liver. Br J Cancer. 1999; 80:1342-1349. [PubMed: 10424734]

18. Scheffer GL, Hu X, Pijnenborg AC, Wijnholds J, Bergen AA, Scheper RJ. MRP6 ( $A B C C 6)$ detection in normal human tissues and tumors. Lab Invest. 2002; 82:515-518. [PubMed: 11950908]

19. Ringpfeil F, Pulkkinen L, Uitto J. Molecular genetics of pseudoxanthoma elasticum. Exp Dermatol. 2001; 10:221-228. [PubMed: 11493310] 
20. Pulkkinen L, Nakano A, Ringpfeil F, Uitto J. Identification of ABCC6 pseudogenes on human chromosome 16p: implications for mutation detection in pseudoxanthoma elasticum. Hum Genet. 2001; 109:356-365. [PubMed: 11702217]

21. Pfendner EG, Vanakker O, Terry SF, et al. Mutation detection in the ABCC6 gene and genotypephenotype analysis in a large international case series affected by pseudoxanthoma elasticum. $\mathrm{J}$ Med Genet. 2007; 44:621-628. [PubMed: 17617515]

22. Iliás A, Urban Z, Seidl TL, et al. Loss of ATP-dependent transport activity in pseudoxanthoma elasticum-associated mutants of human ABCC6 (MRP6). J Biol Chem. 2002; 277:16860-16867. [PubMed: 11880368]

23. Belinsky MG, Chen ZS, Shchaveleva I, Zeng H, Kruh GD. Characterization of the drug resistance and transport properties of multi-drug resistance protein 6 (MRP6, ABCC6). Cancer Res. 2002; 62:6172-6177. [PubMed: 12414644]

24. Klement JF, Matsuzaki Y, Jiang QJ, et al. Targeted ablation of the ABCC6 gene results in ectopic mineralization of connective tissues. Mol Cell Biol. 2005; 25:8299-8310. [PubMed: 16135817]

25. Gorgels TG, Hu X, Scheffer GL, et al. Disruption of Abcc6 in the mouse: Novel insight in the pathogenesis of pseudoxanthoma elasticum. Hum Mol Genet. 2005; 14:1763-1773. [PubMed: 15888484]

26. Pfendner E, Uitto J, Gerard GF, Terry SF. Pseudoxanthoma elasticum: genetic diagnostic markers. Expert Opinion Med Diagn. 2008; 2:1-17.

27. Dawson RJ, Locher KP. Structure of a bacterial multidrug ABC transporter. Nature. 2006; 443:180-185. [PubMed: 16943773]

28. Dawson RJ, Locher KP. Structure of the multidrug ABC transporter Sav1866 from Staphylococcus aureus in complex with AMP-PNP. FEBS Lett. 2007; 581:935-938. [PubMed: 17303126]

29. Ward A, Reyes CL, Yu J, Roth CB, Chang G. Flexibility in the ABC transporter MsbA: Alternating access with a twist. Proc Natl Acad Sci U S A. 2007; 104:19005-19010. [PubMed: 18024585]

30. DeGorter MK, Conseil G, Deeley RG, Campbell RL, Cole SP. Molecular modeling of the human multidrug resistance protein 1 (MRP1/ABCC1). Biochem Biophys Res Commun. 2008; 365:29_ 34. [PubMed: 17980150]

31. O'Mara ML, Tieleman DP. P-glycoprotein models of the apo and ATP-bound states based on homology with Sav1866 and MalK. FEBS Lett. 2007; 581:4217-4222. [PubMed: 17706648]

32. Uitto J, Pulkkinen L, Ringpfeil F. Molecular genetics of pseudoxanthoma elasticum: a metabolic disorder at the environment-genome interface? Trends Mol Med. 2001; 7:13-17. [PubMed: 11427982]

33. Jiang Q, Uitto J. Pseudoxanthoma elasticum: a metabolic disease? J Invest Dermatol. 2006; 126:1440-1441. [PubMed: 16778810]

34. Jiang Q, Li Q, Uitto J. Aberrant mineralization of connective tissues in a mouse model of pseudoxanthoma elasticum: systemic and local regulatory factors. J Invest Dermatol. 2007; 127:1392-4102. [PubMed: 17273159]

35. Le Saux O, Bunda S, VanWart CM, et al. Serum factors from pseudoxanthoma elasticum patients alter elastic fiber formation in vitro. J Invest Dermatol. 2006; 126:1497-1505. [PubMed: 16543900]

36. Jiang Q, Endo M, Dibra F, Wang K, Uitto J. Pseudoxanthoma elasticum is a metabolic disease. J Invest Dermatol. 2008 in press.

37. Capla JM, Ceradini DJ, Tepper OM, et al. Skin graft vascularization involves precisely regulated regression and replacement of endothelial cells through both antiogenesis and vasculogenesis. Plast Reconstr Surg. 2006; 117:836-844. [PubMed: 16525274]

38. Passi A, Albertini R, Baccarani Contri M, et al. Proteoglycan alterations in skin fibroblast cultures from patients affected with pseudoxanthoma elasticum. Cell Biochem Funct. 1996; 14:111-120. [PubMed: 8640951]

39. Quaglino D, Boraldi F, Barbieri D, Croce A, Tiozzo R, Pasquali-Ronchetti I. Abnormal phenotype of in vitro dermal fibroblasts from patients with pseudoxanthoma elasticum (PXE). Biochim Biophys Acta. 2000; 1501:51-62. [PubMed: 10727849] 
40. Quaglino D, Sartor L, Gabrisa S, et al. Dermal fibroblasts from pseudoxanthoma elasticum patients have raised MMP-2 degradative potential. Biochim Biophys Acta. 2005; 1741:42-47. [PubMed: 15955448]

41. Sakuraoka K, Tajima S, Nishikawa T, Seyama Y. Biochemical analyses of macromolecular matrix components in patients with pseudoxanthoma elasticum. J Dermatol. 1994; 21:98-101. [PubMed: 8182219]

42. Lebwohl M, Schwartz E, Lemlich G, Lovelace O, Shaikh-Bahai F, Fleischmajer R. Abnormalities of connective tissue components in lesional and non-lesional tissue of patients with pseudoxanthoma elasticum. Arch Dermatol Res. 1993; 285:121-126. [PubMed: 8503691]

43. Neldner KH. Pseudoxanthoma elasticum. Clin Dermatol. 1988; 6:1-159. [PubMed: 3359381]

44. Baccarani-Contri M, Bacchelli B, Boraldi F, et al. Characterization of pseudoxanthoma elasticumlike lesions in the skin of patients with beta-thalassemia. J Am Acad Dermatol. 2001; 44:33-39. [PubMed: 11148474]

45. Hamlin N, Beck K, Bacchelli B, Cianciulli P, Pasquali-Ronchetti I, Le Saux O. Acquired pseudoxanthoma elasticum-like syndrome in beta-thalassaemia patients. Br J Haematol. 2003; 122:852-854. [PubMed: 12930400]

46. Pasquali-Ronchetti I, Garcia-Fernandez MI, Boraldi F, et al. Oxidative stress in fibroblasts from patients with pseudoxanthoma elasticum: possible role in the pathogenesis of clinical manifestations. J Pathol. 2006; 208:54-61. [PubMed: 16261549]

47. Zarbock R, Hendig D, Szliska C, Kleesiek K, Götting C. Pseudoxanthoma elasticum: genetic variations in antioxidant genes are risk factors for early disease onset. Clin Chem. 2007; 53:17341740. [PubMed: 17693525]

48. Li Q, Jiang Q, Uitto J. Pseudoxanthoma elasticum: oxidative stress and antioxidant diet in a mouse model $\left(\right.$ Abcc6 $\left.^{-/}\right)$. J Invest Dermatol. 2008; 128:1160-1164. [PubMed: 18049453]

49. Mueller CF, Widder JD, McNally JS, McCann L, Jones DP, Harrison DG. The role of the multidrug resistance protein-1 in modulation of endothelial cell oxidative stress. Circ Res. 2005; 97:637-644. [PubMed: 16123331]

50. Cole SP, Deeley RG. Transport of glutathione and glutathione conjugates by MRP1. Trends Pharmacol Sci. 2006; 27:438-446. [PubMed: 16820223]

51. Shearer MJ. Role of vitamin $\mathrm{K}$ and Gla proteins in the pathophysiology of osteoporosis and vascular calcification. Curr Opin Clin Nutr Metab Care. 2000; 3:433-438. [PubMed: 11085828]

52. Hendig D, Arndt M, Szliska C, Kleesiek K, Götting C. SPP1 promoter polymorphisms: identification of the first modifier gene for pseudoxanthoma elasticum. Clin Chem. 2007; 53:829836. [PubMed: 17384004]

53. Renie WA, Pyeritz RE, Combs J, Fine SL. Pseudoxanthoma elasticum: high calcium intake in early life correlates with severity. Am J Med Genet. 1984; 19:235-244. [PubMed: 6507474]

54. Sherer DW, Singer G, Uribarri J, et al. Oral phosphate binders in the treatment of pseudoxanthoma elasticum. J Am Acad Dermatol. 2005; 53:610-615. [PubMed: 16198780]

55. LaRusso J, Jiang Q, Li Q, Uitto J. Ectopic mineralization of connective tissue in Abcc6 $6^{-/-}$mice: effects of dietary modifications and a phosphate binder - a preliminary study. Exp Dermatol. 2008; 17:203-207. [PubMed: 17979973]

56. Le Corvaisier-Pieto C, Joly P, Thomine E, Lair G, Lauret P. Generalized pseudoxanthoma elasticum combined with vitamin $\mathrm{K}$ dependent clotting factors deficiency. Ann Dermatol Venereol. 1996; 123:555-558. [PubMed: 9615107]

57. Rongioletti F, Bertamino R, Rebora A. Generalized pseudoxanthoma elasticum with deficiency of vitamin K-dependent clotting factors. J Am Acad Dermatol. 1989; 21:1150-1152. [PubMed: 2808851]

58. Vanakker OM, Martin L, Gheduzzi D, et al. Pseudoxanthoma elasticum-like phenotype with cutis laxa and multiple coagulation factor deficiency represents a separate genetic entity. J Invest Dermatol. 2007; 127:581-587. [PubMed: 17110937]

59. Li Q, Grange DK, Armstrong NL, et al. Mutations in the GGCX and ABCC6 genes in a family with pseudoxanthoma elasticum-like phenotypes. J Invest Dermatol. 2008 in press. 
60. Gheduzzi D, Boraldi F, Annovi G, et al. Matrix Gla protein is involved in elastic fiber calcification in the dermis of pseudoxanthoma elasticum patients. Lab Invest. 2007; 87:998-1008. [PubMed: 17724449]

61. Li Q, Jiang Q, Schurgers LJ, Uitto J. Pseudoxanthoma elasticum: Reduced gamma-glutamyl carboxylation of matrix gla protein in a mouse model (Abcc6-/-). Biochem Biophys Res Commun. 2007; 364:208-213. [PubMed: 17942075]

62. Berkner KL. The vitamin K-dependent carboxylase. Ann Rev Nutr. 2005; 25:127-149. [PubMed: 16011462]

63. Borst P, van de Wetering K, Schlingemann R. Does the absence of ABCC6 (Multidrug Resistance Protein 6) in patients with pseudoxanthoma elasticum prevent the liver from providing sufficient vitamin K to the periphery? Cell Cycle. 2008; 7:1575-1579. [PubMed: 18469514]

64. Chang M, Shi M, Forman HJ. Exogenous glutathione protects endothelial cells from menadione toxicity. Am J Physiol. 1992; 262:L637-643. [PubMed: 1350424]

65. Lim JI, Bressler NM, Marsh MJ, Bressler SB. Laser treatment of choroidal neovascularization in patients with angioid streaks. Am J Ophthalmol. 1993; 116:414-423. [PubMed: 7692728]

66. Roth DB, Estafanous M, Lewis H. Macular translocation for subfoveal choroidal neovascularization in angioid streaks. Am J Ophthalmol. 2001; 131:390-392. [PubMed: 11239882] 

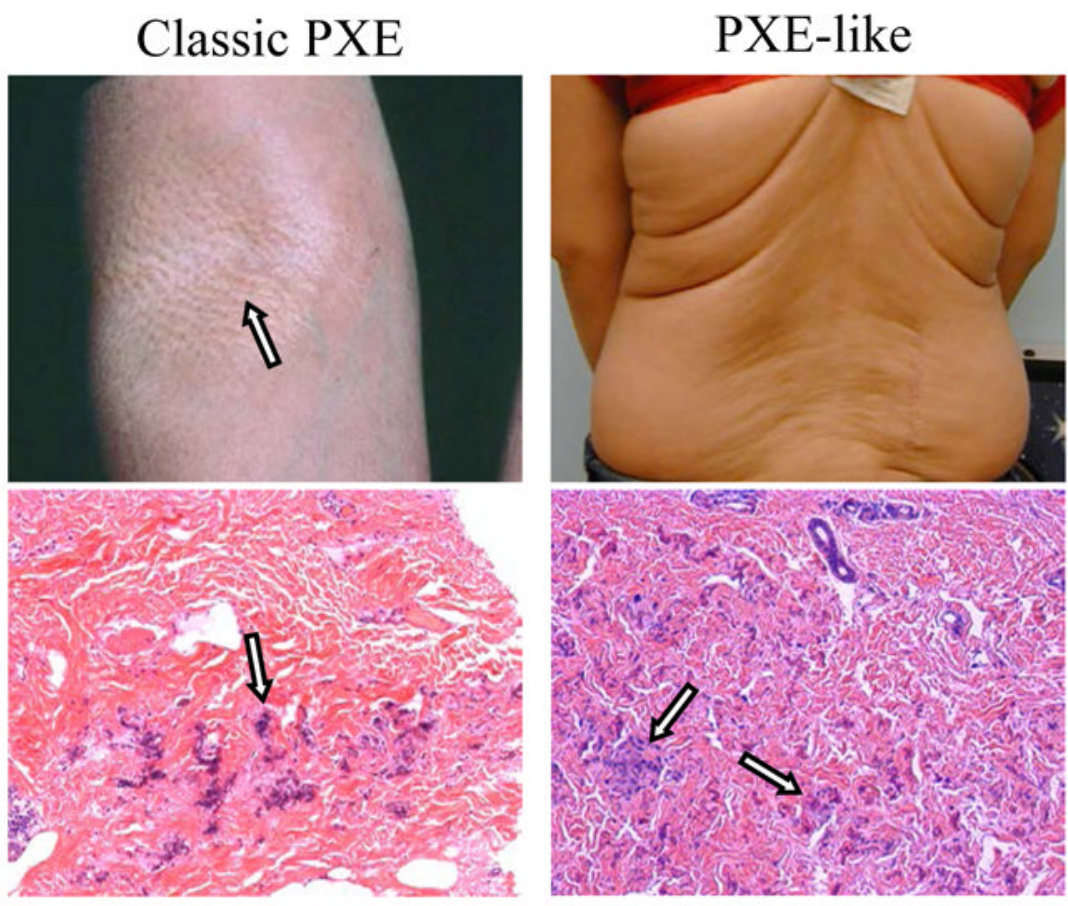

\section{Clinical}

H\&E
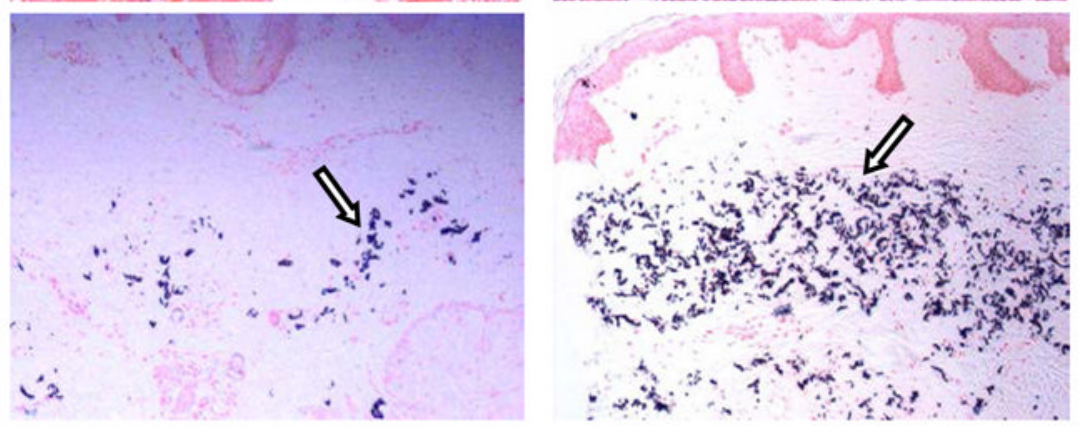

von Kossa
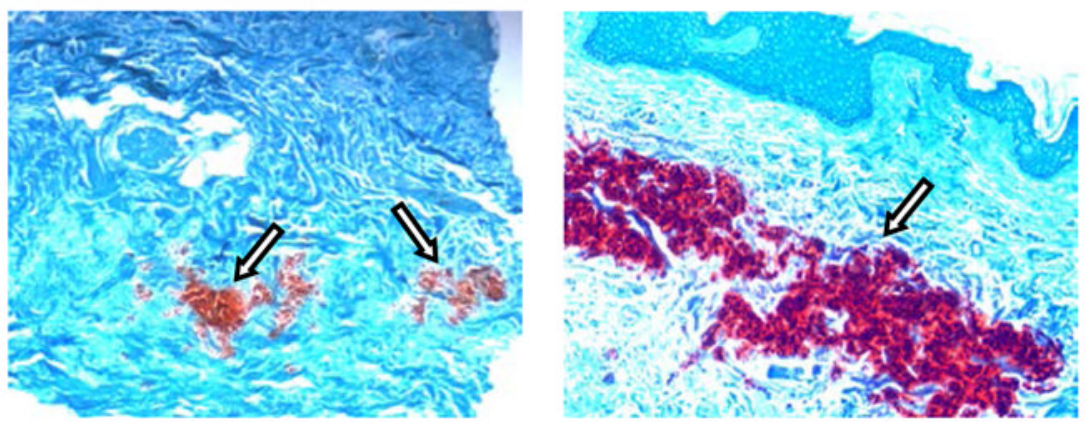

Alizarin Red

Figure 1.

Clinical and histopathologic features of a patient with the classic form of PXE (left panel) as well as in a patients with PXE-like cutaneous features and coagulation deficiency (right panel). On the left, the patient demonstrates characteristic yellowish papules on the antecubital fossa, and skin biopsy of these lesions, when evaluated by Hematoxylin and Eosin stain, shows basophilic, elastotic material in the mid dermis (arrow). Special stains for phosphate and calcium (von Kossa and Alizarin Red stains, respectively) reveal mineralization of the elastotic material. In a 15-year old patient with PXE-like clinical features (right panel) there is evidence of yellowish primary lesions similar to those seen in classic PXE, in addition to redundant, loose and sagging skin. Histopathology is similar to 
that in the patient with the classic form of PXE. Note that the classic form of PXE shows early changes with less mineralization. (Modified from reference 59, with permission). 
$\mathbf{a}$
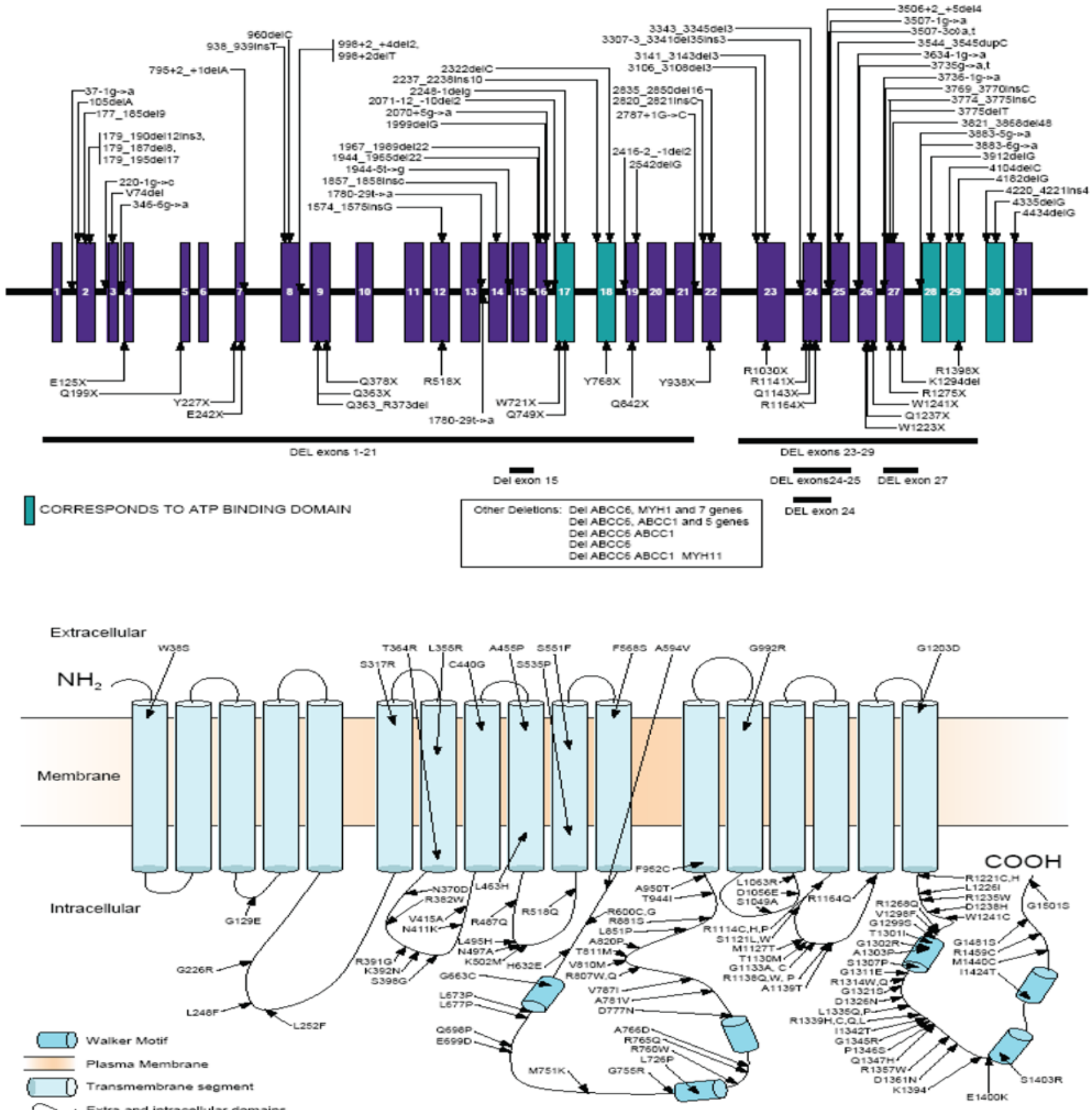

Figure 2.

Schematic representation of the $A B C C 6$ gene (a) and the encoded protein, ABCC6 (b), together with positions of mutations identified in patients with PXE. (a) The $A B C C 6$ gene consists of 31 distinct exons (vertical blocks), some of which encode the two ATP binding domains (green exons). The arrows point to the positions of nonsense, splicing, and small insertion or deletion mutations identified in the gene. Positions of large deletions spanning multiple exons or even the entire gene are indicated below the figure. (b) The ABCC6 putative transporter protein consists of three transmembrane domains each depicting 5, 6 or 6 transmembrane segments (light blue) that traverse the plasma membrane, respectively. The protein domains corresponding to the Walker motifs within the ATP binding domains are 
highlighted by dark green color. Positions of missense mutations identified in the $A B C C 6$ gene are indicated by arrows. (Modified from reference 21, with permission). 


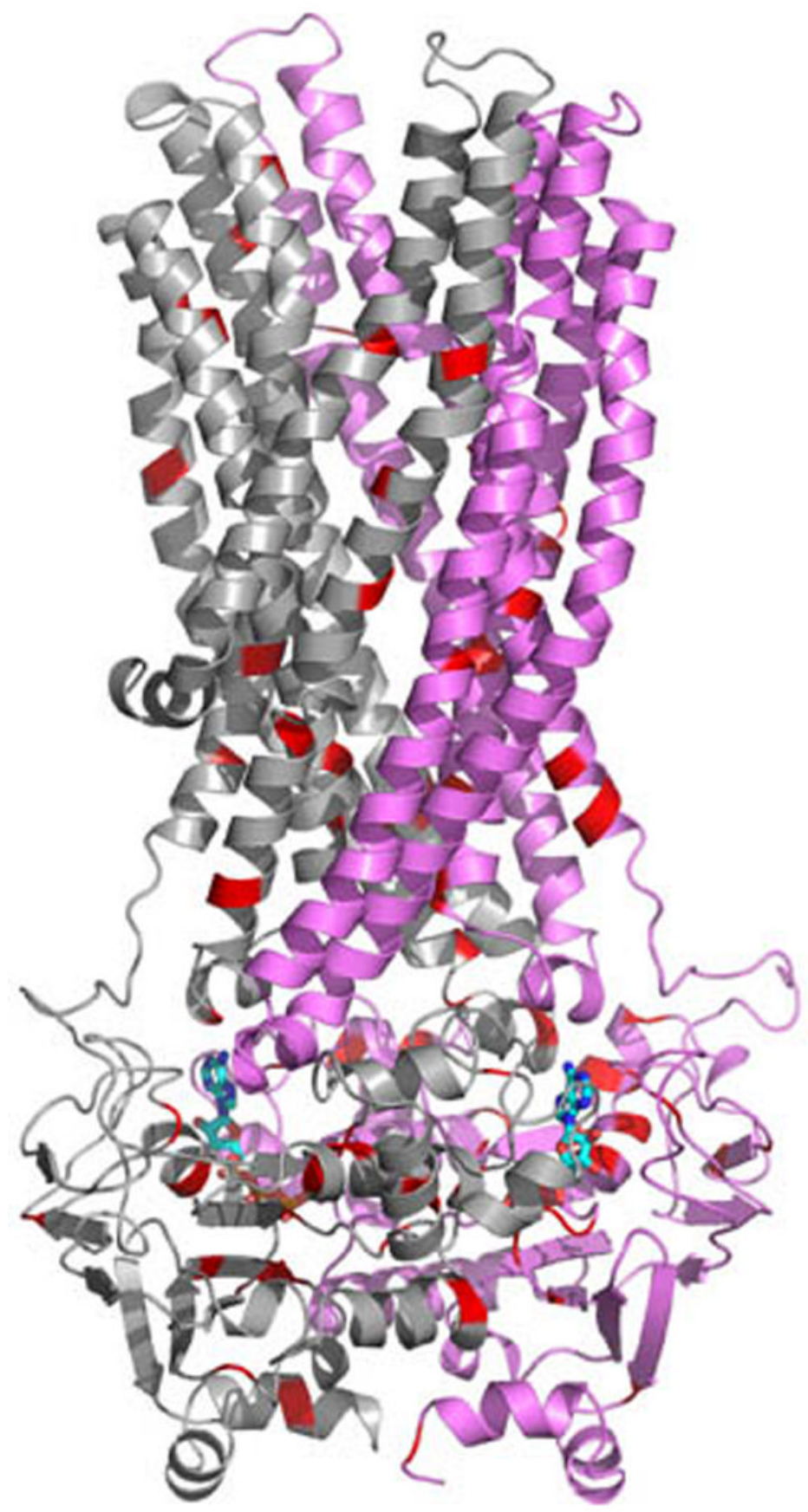

Figure 3.

Distribution of missense mutations on the homology model of human ABCC6. For model building, regions aa288-856 (TMD 1 - $\mathrm{ABC} 1)$ and aa948-1503 $\left(\mathrm{TMD}_{2}-\mathrm{ABC} 2\right)$ were considered and the Sav1866 structure with the nucleotide AMP-PNP (PDB:20NJ) was utilized as a template. The two halves of the molecule are indicated with different colors, pink and olive (only the polypeptide backbones are visualized). PXE-associated missense mutations are highlighted with red color, and two bound nucleotides are indicated by dark green. 

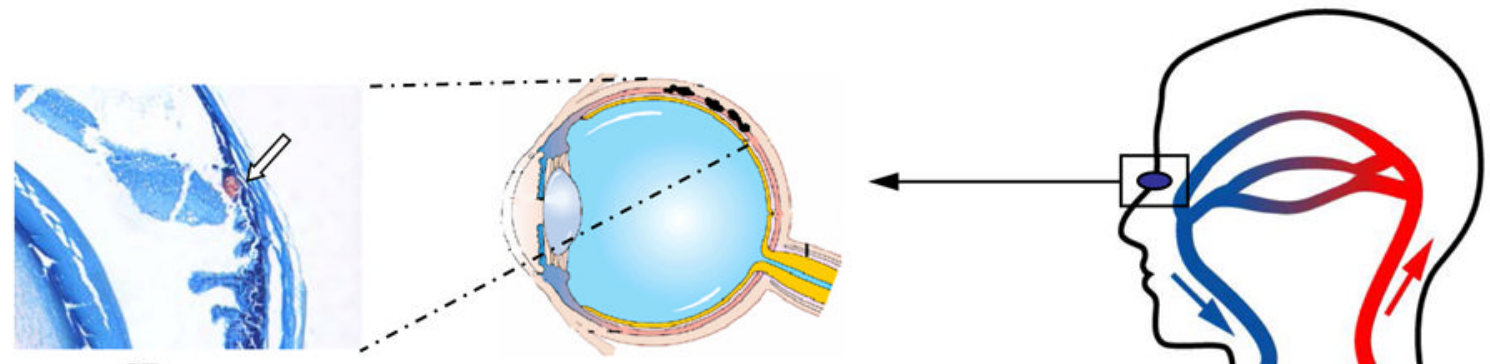

Eye

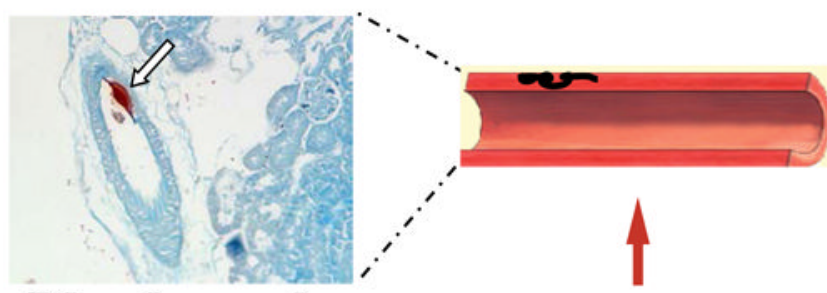

\section{Blood vessel}

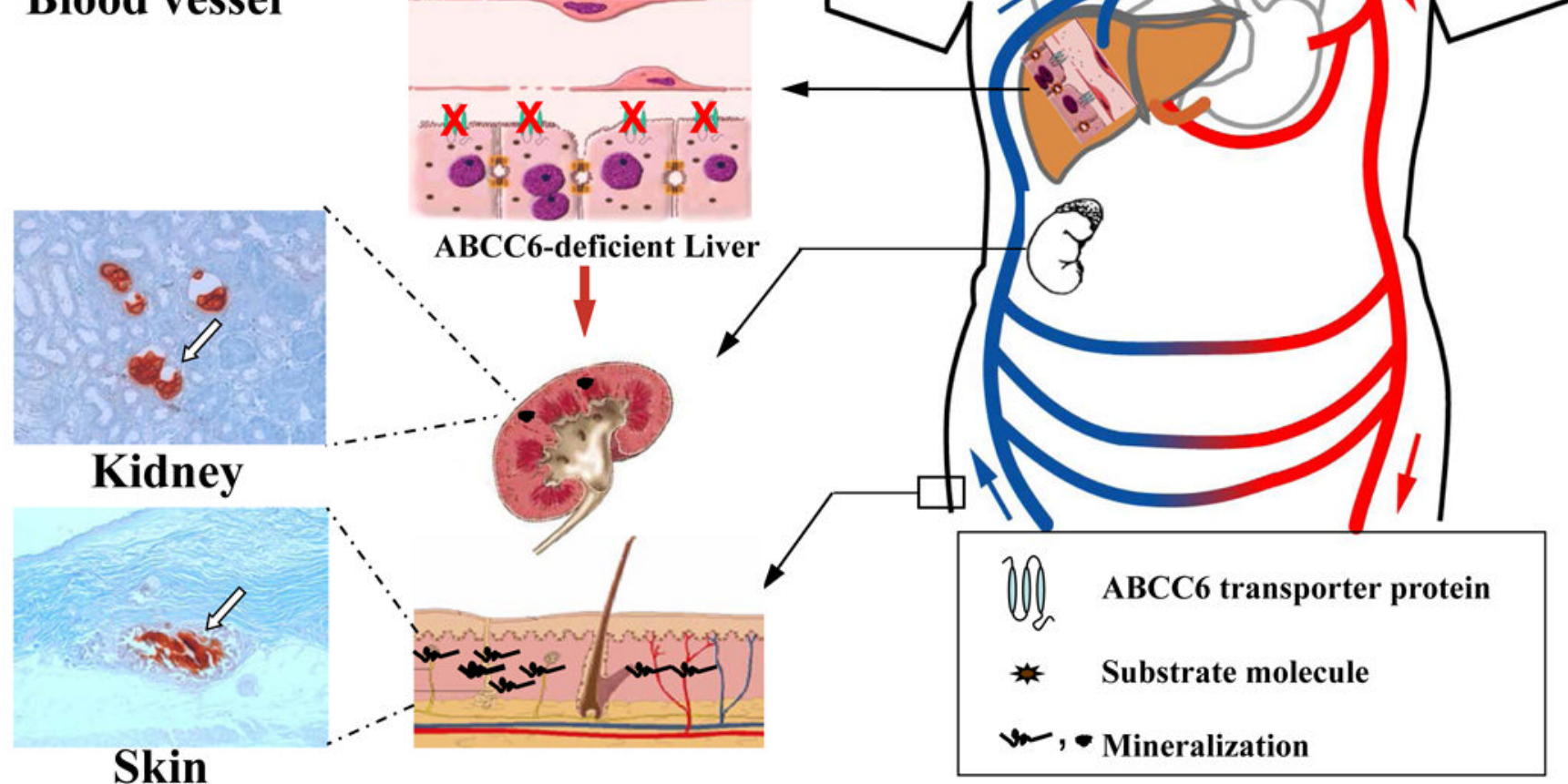

Figure 4.

Conceptual illustration of the proposed metabolic hypothesis of PXE. Under physiologic conditions, the ABCC6 protein is expressed in high levels in the liver, presumably transporting critical metabolites to the circulation (right panel). In the absence of ABCC6 transporter activity in the liver, changes in the concentration of such substrate molecules in the circulation can take place, and the changes result in mineralization of a number of tissues, such as the eye, the arterial blood vessels, the kidney, and the skin (middle panel). The presence of mineralization is detected in transgenic $A b c c \sigma^{--}$mice, that recapitulate the features of human PXE, by Alizarin Red stain. (Modified from reference 33, with permission). 


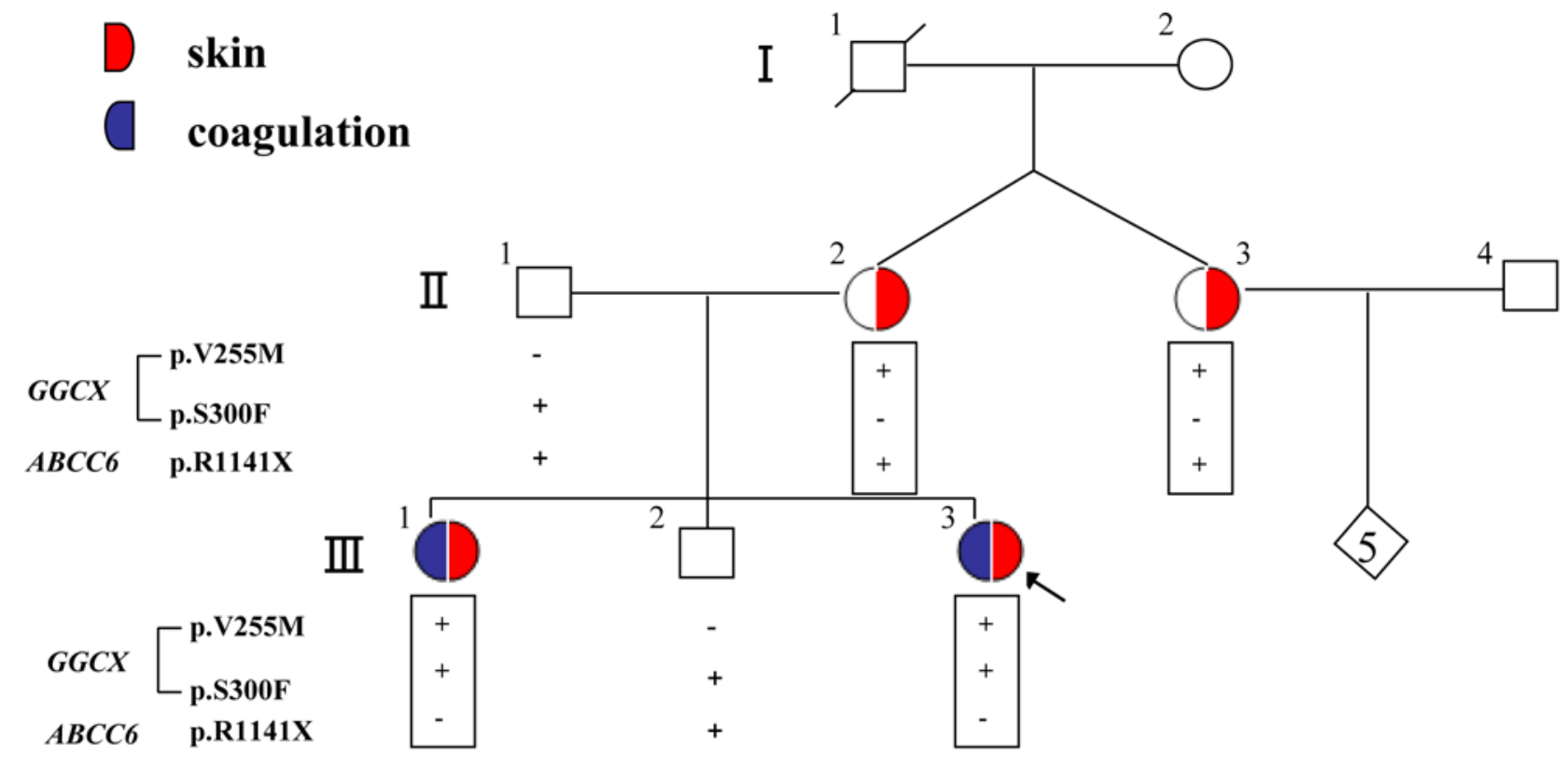

Figure 5.

Detection of mutations in the $G G C X$ and $A B C C 6$ genes in a family with PXE-like cutaneous phenotype in association with vitamin K-dependent multiple coagulation factor deficiency. The proband, whose clinical features are shown in Figure 1, is identified by an arrow. Mutation analysis in the nuclear pedigree identified the presence of the p.R1141X nonsense mutation in the $A B C C 6$ gene and two missense mutations, p.V255M and p.S300F, in the $G G C X$ gene, as indicated on the left. (Modified from reference 59, with permission). 


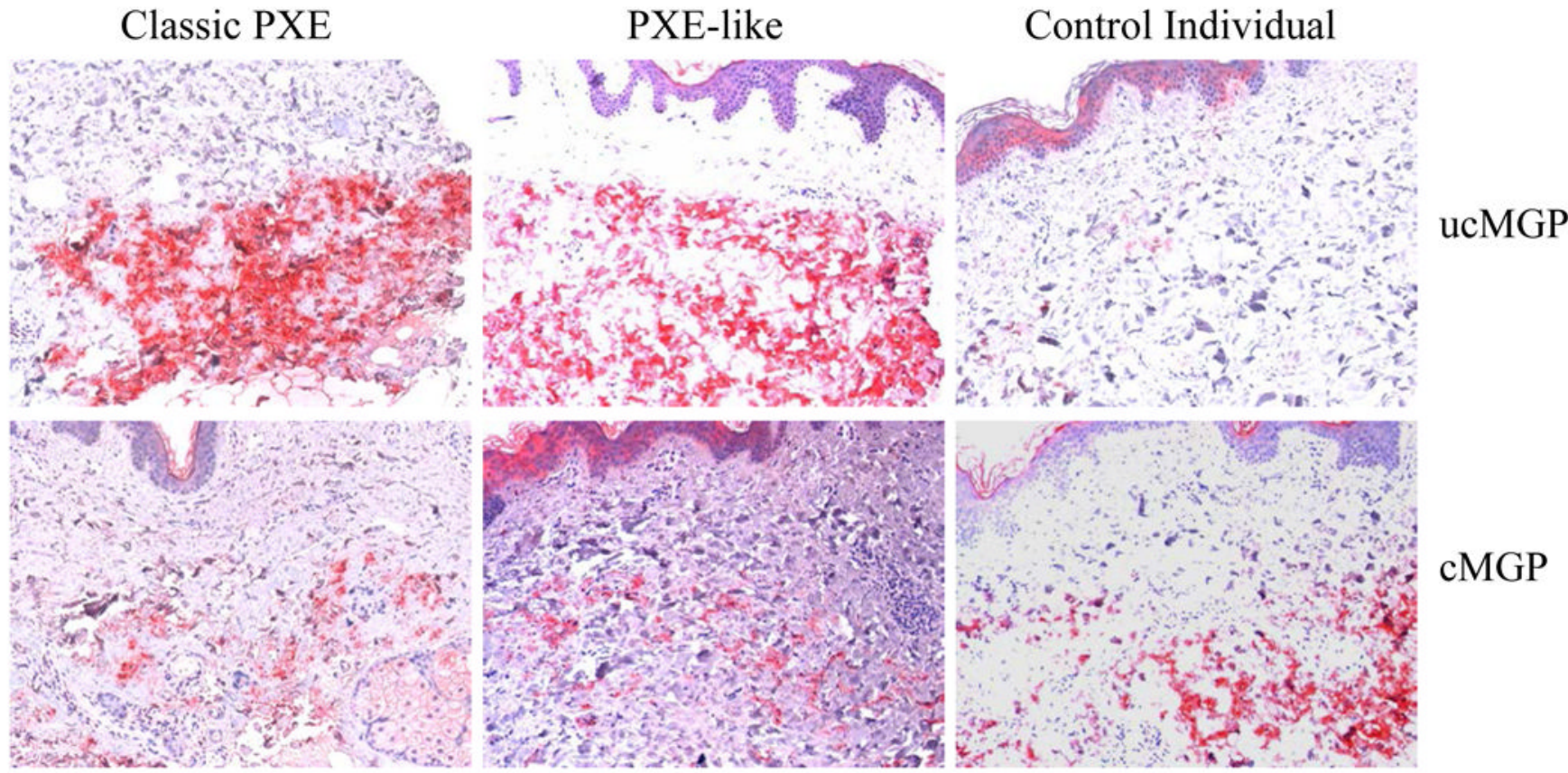

Figure 6.

Demonstration that the matrix gla protein (MGP) is under-carboxylated in the lesional skin of a patient with classic form of PXE (left panel) as well in a patient with PXE-like cutaneous features from the family in Figure 5 (middle panel), as compared to skin from a control individual (right panel). Skin biopsies were stained with specific antibodies recognizing either the under-carboxylated (ucMGP) or the carboxylated (cMGP) forms of MGP. The secondary antibodies consisted of biotin-conjugated anti-IgG, recognized by avidin-alkaline phosphatase conjugates, and visualized by incubation with an alkaline phosphatase substrate yielding red color (Modified from reference 59, with permission). 

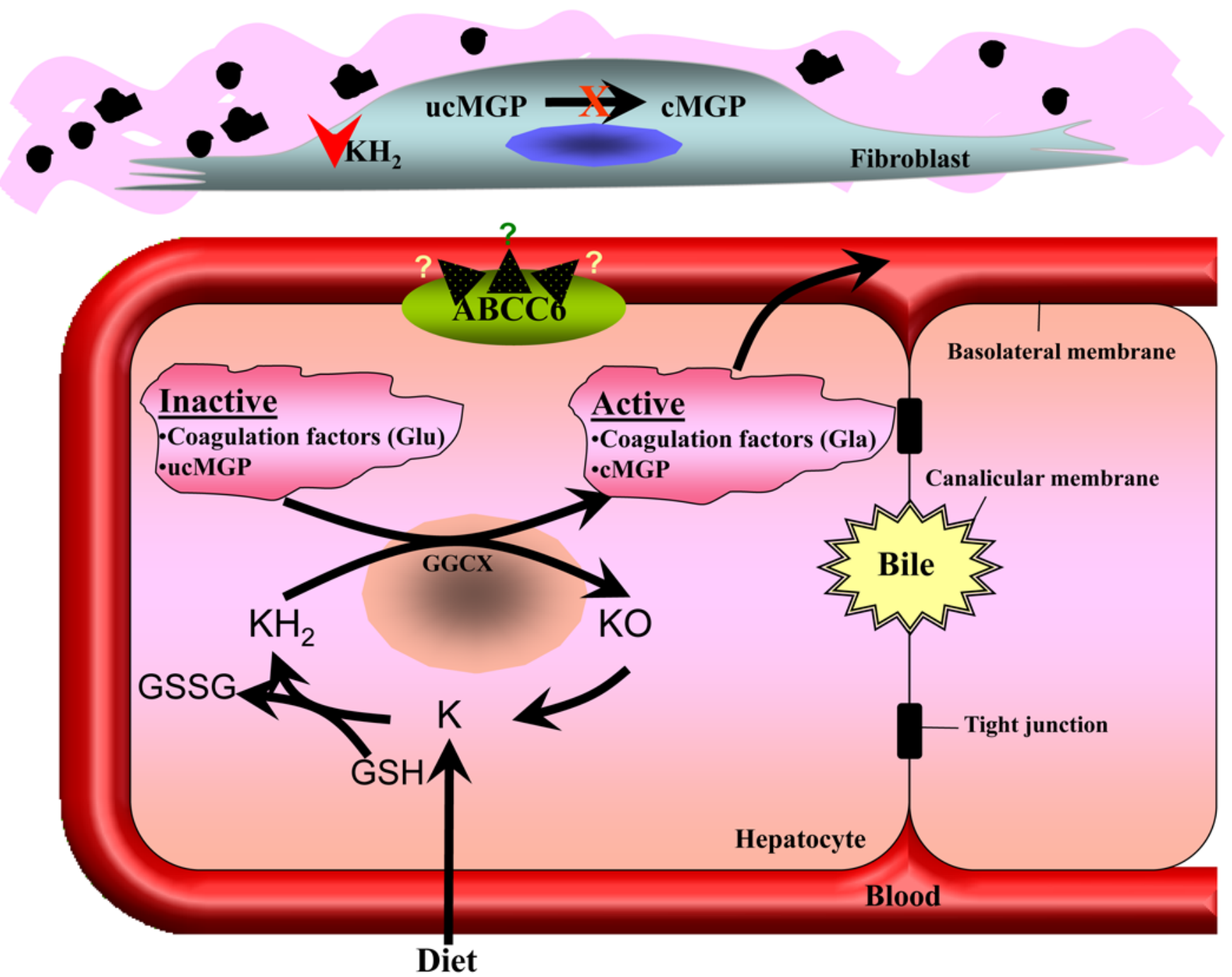

Figure 7.

Speculative schematic representation of the activation of blood coagulation factors (Glu) and under-carboxylated matrix gla protein (ucMGP) by $\gamma$-glutamyl carboxylation.

Lower panel: The active $\gamma$-glutamyl carboxylated forms of the coagulation factors (Gla) and carboxylated matrix gla protein (cMGP) are secreted into circulation from hepatocytes and are required for normal blood coagulation and prevention of unwanted mineralization of peripheral tissues, respectively. The $\gamma$-glutamyl carboxylase is encoded by the $G G C X$ gene and is dependent on reduced vitamin $\mathrm{K}\left(\mathrm{KH}_{2}\right)$ as a co-factor in the liver. The oxidized forms of vitamin $\mathrm{K}(\mathrm{KO})$ and the dietary vitamin $\mathrm{K}$ are reduced back to $\mathrm{KH}_{2}$ by enzymatic reactions coupled with conversion of GSH to GSSG. The role of ABCC6, the transmembrane efflux transporter, in this process is currently unknown.

Upper panel: One could hypothesize that the ABCC6 protein transports vitamin K, possibly in its glutathione conjugated form, from the liver into circulation and to the peripheral tissues. Consequently, cells in peripheral tissues, such as fibroblasts in the skin, lack the ability to convert inactive ucMGP to active, fully carboxylated cMGP, possibly due to lack of $\mathrm{KH}_{2}$. Thus, deficiency of cMGP in the resident fibroblasts allows pathologic mineralization of connective tissues deposited in the pericellular matrix to proceed, resulting in PXE. 